\title{
ПЕРСПЕКТИВЫ ПРОМЫШЛЕННОГО ПРИМЕНЕНИЯ ТЕХНОЛОГИЙ ИНТЕРНЕТ ВЕЩЕЙ: ОГРАНИЧЕНИЯ И ПРЕИМУЩЕСТВА
}

\author{
(c) 2019 Мясоедов Сергей Александрович \\ доктор экономических наук, доцент \\ Академия маркетинга и социально-информационных технологий - ИМСИТ, Россия, Краснодар \\ E-mail:myasoedov8@mail.ru
}

Аннотация: ускоряющаяся цифровизация экономических процессов, доступность информационных устройств способствует развитию информационных технологий, обеспечивающих снижение уровня потребления ресурсов и повышающих эффективность управления; внедрение технологий интернет вещей влечёт за собой и рост потенциала киберугроз, трансформирует реальность низкого уровня доходов населения страны в сдерживающий фактор внедрения цифровых технологий в экономику. Технологии интернет вещей востребованы всеми группами населения и сферами экономики, представляют собой колоссальную перспективу для эффективности инвестиций в производство устройств, компонентов, инфраструктуру данного сегмента цифровой экономики.

Ключевые слова: цифровая экономика, интернет вещей, технологии «умный город», технологии «умный дом», большие данные, шеринговая экономика.

Технологии интернет вещей, в отличии от технологий биг дата и сегментов шеринговой экономики имеют более широкий спектр практического применения, связанный с востребованностью как юридическими, так и физическими лицами.

Технологии интернет вещей (Internet of Things (сокращенно IoT)) предполагают наличие полностью автоматизированного цикла работы вещей из реального мира при взаимосвязи с виртуальным миром: когда Ваш холодильник передаёт сообщения на телефон о необходимости пополнить запас конкретных продуктов; когда сообщается о том, что водитель отклонился от маршрута; когда у наблюдаемого пациента на улице повысилось давление и датчики контроля автоматически сообщили лечащему врачу и вызвали скорую помощь; когда приходит оповещение о том, что автомобильная пробка увеличивается и синхронно приходит команда об увеличении продолжительности активной фазы зелёного сигнала светофора в нужном направлении; когда сообщают о протечке водопроводной трубы. Иными словами, в виртуальном мире появляется агент с искусственным интеллектом, который выполняет поставленные задачи.

Технологии интернет вещей предусматривают трансформацию как образа жизни, ментальности, так и корректировку бизнес процессов, культуры управления [2].

Рынок ІоТ-технологий бурно развивается и для его бесперебойной работы требуется обеспечение трёх основных составляющих:

1. исходными компонентами для производства, сборки ІоТ-устройств (различные типы чипов, датчиков, микро и нано процессоров и компьютеров);

2. ІоТ- устройствами;

3. информационными платформами, инфраструктурой, обеспечивающие передачу данных на сервера и т.д.

IоТ-технологии в промышленно развитых государствах активно применяются в следующих направлениях: энергетика, сельское хозяйство, медицина, логистическая сфера, технологии «Умный город» и «Умный дом».

1. Электроэнергетика

Применение цифровых технологий, IоT-устройств обеспечивает получение информации о наличиисвободных объёмов электроэнергии, о её цене в момент предполагаемого потребления.

Клиент, приобретающий электричество, получает информацию о её стоимости в момент потребления и может выбирать периоды времени(например, ночь), когда ресурс реализуется поставщиками по минимальной цене, тем самым снижать свои издержки и, понижать потребление в период «пиковых» нагрузок.

Применение данных технологий повышает надёжность электрических сетей, снижает число перегрузок и аварий.

В странах, где применяются подобные тех- 
нологии потребитель выбирает самостоятельно у кого поставщика он покупает электричество.

В результате плюсы от внедрения ІоТ-технологий:

- повышается эффективность генерации и распределения электроэнергии;

- снижаются затраты у конечного потребителя;

- происходит выравнивание нагрузки на сеть;

- сокращение потерь электричества от перегрева передающих устройств, аварий;

- оптимизация производства, включая продажу физическими или юридическими лицами произведённой электроэнергии генерациями (в ряде государств мира).

Минусы применения ІоТ-устройств связаны:

- дороговизной инвестиционных проектов;

- возможная несовместимость созданных платформ для адаптации к российским устройствам, оборудованию;

- ограниченное число или отсутствие специалистов соответствующей квалификации по внедрению и обслуживанию ІоТ-устройств;

- рост возможностей по проведению операций по организации и проведению киберугроз, кибератак в энергетике с увеличением объёма информации о работе объектов электросетей, генераций, с возможностью подключения различный электронных устройств к сетям.

2. Здравоохранение.

Интеллектуальные системы в здравоохранении активно применяются при проведении ранней диагностики, при мониторинге показателей жизнедеятельности организма на расстоянии лечащими специалистами (удалённый мониторинг), дистанционное взаимодействие «врач-пациент», «врач-врачи» (технологии телемедицины), медицинская аналитика.

Для таких целей используют микродатчики, чипы, сенсоры на уровне нано размеров, с целью выявления, например, сердечной недостаточности, очагов заражения, осложнений.

Результативно на практике применяются IоT-устройства в операционных палатах, в палатах интенсивной терапии, в период послеоперационной помощи в стационарах, для контроля приёма медикаментов.

Применение технологий в здравоохранении осуществляется не только по лечебному направлению (лечению, уходу, диагностике), но и в системе администрирования и управления лечеб- ным заведением, контроля за объёмами запасов медицинских препаратов, локации переносного медицинского оборудования, оценке деятельности медицинского персонала.

Применение ІоТ-устройств позволяет:

- оптимизировать величину запасов медикаментов и оборудования;

- сбалансировать нагрузку медицинского персонала;

- снизить затраты на лечение;

- повысить эффективность лечебной деятельности, в направлении диагностики, мониторинга, получения квалифицированных консультаций.

Ограничения по внедрению ІоТ-устройств в медицине:

- юридические ограничения, а именно

a) наличие неразвитой правовой базы для применения ІоТ-устройств в здравоохранении при оказании удалённой медицинской помощи, в использовании технологий дистанционного мониторинга, процедур постановки диагноза, выписке электронных рецептов, при определении местоположения пациента и т.д.

б) сложность применения процедур регистрации либо отсутствие правовых норм регистрации ІоТ-устройств;

- защита персональных данных, телекоммуникационных каналов. Кибербезопасность, защита персональных медицинских данных, высокое качество передающих устройств, защита каналов связи;

- социальные, в том числе отрицание в обществе и профессиональном сообществе эффективность удалённого мониторинга, лечения; и применения общепринятой системывзаимодействия «врач-пациент» и «врач-врач» и системы работы с реальным, а не виртуальным пациентом;

- отсутствие необходимого количества специалистов по информационным технологиям;

- значительные инвестиции во внедрение IоT-устройств и технологий, а также в организацию их обслуживания, что приведёт к удорожанию конечных медицинских услуг.

3. Сельское хозяйство

В целом, как показывает практика, сельхозпроизводитель в России мало заинтересован в применении ІоТ-устройств, так как дешёвая рабочая сила компенсирует все возможные экономические эффекты от использования IоT-y- 
стройств.

По мнению экспертов сельское хозяйство Российской Федерации считается технологически отсталым, что приводит к низкой производительности труда.

ІоТ-устройства в сельском хозяйстве способны внедрять только крупные хозяйствующие субъекты.

Перспективными направлениями применения ІоТ-устройств считаются системы мониторинга в растениеводстве (за влажностью почвы в теплицах, за интенсивностью освещениями т.д.) и животноводстве (за уровнем надоя за каждой головой КРС, за соблюдением норм кормления и т.д.).

Плюсы от внедрения ІоТ-технологий:

- сокращение потерь зерна, ГСМ, удобрений, воды и других ресурсов;

- снижение затрат на оплату труда.

Ограничения, снижающие скорость внедрения ІоТ-технологий:

- низкий уровень покрытия телекоммуникационными сетями сельскохозяйственных территорий, отсутствие должной инфраструктуры, обеспечивающей в режиме реального времени передачу информации с датчиков, цифровых устройств;

- отсутствие соответствующих информационных технологий, позволяющих решать локальные задачи для каждого сельхозтоваропроизводителя;

- низкая стоимость рабочей силы, низкая заработная плата, делающая не целесообразным внедрение ІоТ-технологий;

- большой (не подъёмный) объём инвести- ций при внедрении ІоТ-технологий для подавляющего большинства сельхозтоваропроизводителей.

4. Логистика

В логистической деятельности ІоТ устройства задействованы в системе контроля и управления:

- автотранспортным парком (геолокация, автоматическая диспетчеризация, контроль за потреблением ГСМ, ассистенты помощи водителям),

- автономным транспортом;

- роботизированными складами;

- автоматизированными складскими помещениями.

Плюсы от внедрения ІоТ-технологий в логистической сфере:

- сокращение объёмов запасов на складах, снижение расходов по хранению, транспортировке;

- высокий уровень конкуренции в отрасли, обеспечивающий поиск направлений повышения эффективности деятельности;

- отслеживание параметров системы в любой момент времени (износ, величина нагрузки, предотвращения поломок за счёт анализа данных о состоянии узлов, агрегатов);

- быстрота реакции на изменяющиеся параметры объекта и условий маршрута на всём протяжении следования груза, нефти, газа;

- мониторинг состояния движения по всей цепочки (при перемещении грузов, мониторинг и анализ элементов трубопроводов, передвижного состава, коммуникаций), прозрачность перемещения, проведение мгновенной инвента-

Таблица. Перечень типичных факторов, ограничивающих развитие ІоТ-технологий в энергетике, медицине, сельском хозяйстве, логистике

\begin{tabular}{|c|c|c|c|c|}
\hline \multirow{2}{*}{$\begin{array}{l}\text { Факторы, ограничивающие } \\
\text { внедрение ІоТ-технологий }\end{array}$} & \multicolumn{4}{|c|}{ Уровень влияния ограничения на вероятность внедрения } \\
\hline & Энергетика & Медицина & $\begin{array}{l}\text { Сельское } \\
\text { хозяйство }\end{array}$ & Логистика \\
\hline $\begin{array}{l}\text { Высокая стоимость внедрения } \\
\text { ІоТ-технологий и их обслуживания }\end{array}$ & Средний & Средний & Высокий & Средний \\
\hline $\begin{array}{l}\text { Ограниченное число специалистов, } \\
\text { обслуживающих ІоТ-устройства }\end{array}$ & Высокий & Высокий & Высокий & Высокий \\
\hline $\begin{array}{l}\text { Отсутствие современных техноло- } \\
\text { гий, позволяющих решать локаль- } \\
\text { ные задачи каждой организации. } \\
\text { Не совместимость платформ }\end{array}$ & Высокий & Высокий & Высокий & Высокий \\
\hline $\begin{array}{l}\text { Низкий уровень заработной платы в } \\
\text { отрасли, дешёвая рабочая сила }\end{array}$ & Средний & Высокий & Высокий & Высокий \\
\hline $\begin{array}{l}\text { Рост уровня возникновения киберу- } \\
\text { гроз, защита персональных данных }\end{array}$ & Высокий & Высокий & Средний & Высокий \\
\hline
\end{tabular}


ризации в режиме онлайн;

- внедрение системы идентификации «свой-чужой»;

- возможность накопления данных для последующего анализа сложных моментов после свершения события, аварий, инцидентовс оценкой всех параметров;

- рост уровня контроля за персоналом, водителями, профилактика краж ГСМ и контроль за использованием транспорта в личных целях, повышения эффективности системы стимулирования персонала.

Факторы, ограничивающие внедрение IоT-технологий в логистическую сферу:

- значительные затраты для компаний на внедрение ІоТ-технологий;

- низкая стоимость рабочей силы в Российской Федерации слабо стимулирует использование ІоТ технологий, требующих серьёзных инвестиций в модернизацию производств;

- огромная протяжённость расстояний по внутреннему перемещению грузов и иных объ- ектов, а также сложные климатические условия;

- наличие слаборазвитой инфраструктуры по пути следования объектов.

Исходя из вышеизложенного следует, что к основным сдерживающим факторам развития ІоТ технологий относят:

1. проблему интеграции, совмести искусственного интеллекта в различные сферы экономики при отсутствии универсальных правил и стандартов;

2. наличие постоянного бесперебойного и в ряде случаев мощного источника энергии;

3. практически отсутствие конфиденциальности информации, доступной при IоT технологиях;

4. значительная величина инвестиций при внедрении и обслуживании ІоТ технологий;

5. низкий уровень заработной платы в Российской Федерации, дешёвая рабочая сила, делающая экономически не целесообразным внедрение ІоТ технологий.

\section{Библиографический список}

1. Мясоедов С.А. Анализ концептуальных основ устойчивого экономического развития//Экономические науки.- М.- 2017. № 7(152).- С. 19-22.

2. Мясоедов С.А. Экономическая сегментация цифровой экономики// Вестник ИМСИТа: научно-информационный и учебно-методический журнал.- Краснодар: типография ИМСИТ - 2019. - № 1(77). - С.8-11.

3. Digital in 2017: Global Overview. https://wearesocial.com/sg/ blog/2017/01/digital-in-2017-global-overview 